Research Article

\title{
Prevalence of Alcohol Use and Associated Factors among Dilla University Students, Dilla Town, Southern Ethiopia: A Cross-Sectional Study
}

\author{
Yigrem Ali Chekole $\mathbb{1}$ \\ Department of Psychiatry, College of Medicine and Health Sciences, Dilla University, Dilla, Ethiopia \\ Correspondence should be addressed to Yigrem Ali Chekole; alyigrem@gmail.com
}

Received 13 April 2020; Revised 30 September 2020; Accepted 7 October 2020; Published 19 October 2020

Academic Editor: Richard H. Hammersley

Copyright (C) 2020 Yigrem Ali Chekole. This is an open access article distributed under the Creative Commons Attribution License, which permits unrestricted use, distribution, and reproduction in any medium, provided the original work is properly cited.

\begin{abstract}
Introduction. Globally, alcohol is one of the most prevalent forms of substance use that is particularly high among young age groups. Despite the adverse health and social challenges associated with alcohol use, it is one of the most common risky behaviours among university students. Objective. This study aimed to assess the prevalence of alcohol use and associated factors among Dilla University students in Southern Ethiopia. Methods. An institution-based cross-sectional study was conducted at Dilla University among undergraduate regular students from January to February 2018. A systematic random sampling technique was used to get a total sample of 803 students each year from the department of the university. The collected data were coded, entered into Epi Info version 7.1, and analyzed with SPSS version 20. Results. A total of 803 participants were successfully interviewed with a response rate of $91.7 \%$. Alcohol use prevalence was $41.8 \%(n=336)$ among participants. Being in fourth year (AOR $=2.66,95 \%$ CI: 1.64 , 4.31), having friends who use the substance ( $\mathrm{AOR}=1.53,95 \% \mathrm{CI}: 1.09,2.1)$, being a khat user ( $\mathrm{AOR}=1.48,95 \% \mathrm{CI}: 1.05,2.09)$, and being a cigarette smoker $(\mathrm{AOR}=1.76,95 \% \mathrm{CI}: 1.09,2.84)$ were found to be significantly associated with alcohol use. Conclusion. The current study revealed that fourth-year students, having friends who use the substance, being khat user, and being cigarette smoker had higher odds of alcohol use among the students. So the findings suggest that effective campus-based counselling and peer education should be implemented for early prevention, detection, and alleviation of alcohol use among students in the university.
\end{abstract}

\section{Introduction}

Substance use among adolescents can lead to a variety of detrimental consequences. Cigarette smoking, alcohol drinking, and cannabis use can increase accidental or intentional injuries, commission of crimes, mood disorders, and mortality and can complicate normal psychosocial development [1-3].

The use of substances is one of the rising major public health and socioeconomic problems worldwide, which has dramatically increased particularly in developing countries [4-8]. Substance use in Africa is increasing rapidly, especially for tobacco, alcohol, and khat [9].

Alcohol is one psychoactive substance that has been widely used in many cultures for centuries [10,11]. It is often consumed before, along with, or after other psychoactive substances, and the comorbidity of alcohol and tobacco dependence is strong [12]. Alcohol use causes large disease and social and economic burden in many societies [13].

Harmful use of alcohol accounts for nearly $6.5 \%$ of all deaths in Europe, where alcohol-related harm is highest, and even in the world, but the burden is much higher in certain countries and for certain groups within countries [14]. About 3.3 million deaths, or $5.9 \%$ of all global deaths, were attributable to alcohol use $[11,13]$. There are significant gender differences in the proportion of global deaths attributable to alcohol, for example, $7.6 \%$ of deaths among males and $4.0 \%$ of deaths among females were attributable to alcohol [13].

Younger people are more affected by alcohol than older people. Possibly $13.5 \%$ of all deaths among those who are 20-39 years of age may be attributed to alcohol [12]. An 
estimated 24.6 million Americans aged 12 or older had used an illegal drug, approximately $9.4 \%$ of the population [15]. In most parts of Africa, health and social problems related to alcohol use are increasing. In sub-Saharan Africa, an estimated $1.8 \%$ of the disease burden is attributable to alcohol use $[16,17]$.

In a study done in western Kenya among college students, the lifetime prevalence rate of alcohol use was $51.9 \%$ [18]. Being male, ease of getting an adult to buy alcohol, cigarette use, and having multiple sexual partners were risk factors [11].

About $5.9 \%$ of all global deaths were attributable to alcohol consumption. Global deaths were attributable to alcohol among males (7.6\%) and females (4.0\%) [14].

A study done in western Kenya among college students showed that $75.1 \%$ were introduced to substance use by a friend while $23.5 \%$ were introduced by a relative. Majority of users wanted to relax (62.2\%) or relieve stress (60.8\%) [18].

Over $20 \%$ of out-of-school youth had unprotected sex during the 12 months before the interview compared to $1.4 \%$ of in-school youth. Daily alcohol intake and khat intake were also associated with unprotected sex [19].

One Ethiopian study of Haramaya University students found the prevalence of substance use was high, and about two-thirds $(62.4 \%)$ of the participants used at least one substance, most commonly alcohol (50.2\%) [20].

Another study at Axum University found that the lifetime prevalence of alcohol drinking was $34.5 \%$ and the current prevalence was 32.8\% [21]. Similarly, in Debre Markos University, the prevalence of alcohol drinking was $33.8 \%$ [22].

Another study done in Hawassa found that $40.8 \%$ used alcohol, $20.3 \%$ chewed khat, $11.9 \%$ smoked cigarettes, and $0.9 \%$ used marijuana [23]. In another study among RVUC students, the lifetime prevalence of alcohol drinking was $40.2 \%$. Similarly, the current prevalence of alcohol drinking was $35.6 \%$ [24].

The Hawassa study found that having family members who used psychoactive substances (PAS), peer influence, being male, and living alone during school age were positively associated with overall PAS use in the past 12 months [23]. The most common reasons for use among university students were for relaxation with friends $(84(53.8 \%))$, peer pressure $(72(46.2 \%))$, and to get relief from stress (56 (35.9\%)), respectively [23].

As in many developing countries, alcohol is the most frequently used substance in Ethiopia [6, 25].

Therefore, the present study aimed at assessing the prevalence of alcohol use and associated factors among Dilla University students. The findings are expected to inform university students about the possible dangers of alcohol use and to contribute significantly to national guidelines, targets, policies, and strategies that pertain to the management and evaluation of youth health programs in universities.

\section{Methods and Materials}

2.1. Study Design, Period, and Study Area. The institutionalbased cross-sectional study was conducted from January to
February 2018 among Dilla University students in the Gedeo Zone, Southern Ethiopia, which is found on the main road from Addis Ababa to Kenya $360 \mathrm{~km}$ south of Addis Ababa and $90 \mathrm{~km}$ south of Hawassa (capital of SNNPR). The Gedeo Zone has a longitude and latitude of $6^{\circ} 24^{\prime} 30^{\prime \prime} \mathrm{N} 38^{\circ} 18^{\prime} 30^{\prime \prime} \mathrm{E}$ with an elevation of 1570 meters above sea level [26, 27].

Dilla University is one of the public universities located in the fertile coffee belt of the Gedeo Zone. Its history can be traced back to the year 1996 when it was called Dilla College of Teacher Education and Health Sciences and was included in the then newly emerging University, Debub University in 2001 EC, and became Dilla University in 2004 EC. It has three campuses, six colleges, three schools, and two institutes offering undergraduate and postgraduate programmes. Currently, more than 31,000 students take part in regular, summer, weekend, and distance programmes.

2.2. Sample Size and Sampling Technique. The sample size was determined using a single population proportion formula by an assumption of $p=45.7 \%$, based on a previous study from Southern Ethiopia (Hawassa University) [23] with 95\% confidence interval and 5\% margin of error. Assuming a $15 \%$ nonresponse rate and a design effect of two for multistage sampling, the total sample size was computed to be 876 .

All regular undergraduate students attending at Dilla University were eligible to participate. A multistage sampling technique was used to select the study participants. First, students were divided into their colleges and departments. Then, further stratification was used based on the year of study. Students from each year of study were allocated proportionally to the class size of their departments. " $K$ " was calculated as $12138 \div 876=13.86 \sim 14$ for each year separately. Therefore, the study subjects were selected every 14 from the list of students' names.

2.3. Data Collection Procedures and Instruments. A structured questionnaire adapted from the previous literature on alcohol use was used to collect the data. The questionnaire had different components including sociodemographic, clinical, and alcohol use characteristics. Sociodemographic characteristics included age, sex, religion, ethnicity, monthly income, place of residency, types of high school attended, current living, year of study, friends' psychoactive substance use, and family's psychoactive substance use.

The clinical factors and psychoactive substances included the diagnosis of mental illness, family history of mental illness, history of chronic illness, khat use, and cigarette smoking.

Alcohol use was measured by a 9-item semistructured questionnaire which was prepared by reviewing the WHO students' drug use survey questionnaire, the ASSIST guideline [28], and the relevant previous literature $[6,8,18,22,24,29-32]$. Alcohol, Smoking, and Substance Involvement Screening Test (ASSIST) guideline specifically asked about the following: (1) all substances a participant had ever used in his/her lifetime, (2) frequency of use in the past three months preceding the survey, (3) frequency of 
experiencing a strong desire to use a substance in the past three months preceding the survey, (4) frequency of health, social, legal, or economic problems related to substance use in the past three months preceding the survey, (5) frequency of substance use interfering with students' roles and responsibilities in the past three months preceding the survey, (6) if she/he has a friend or a relative or anyone else ever expressed concern about your use of the substance, and (7) if she/he has ever tried and failed to control, cut down, or stop using the substance. The questions are in increasing order of specificity. The questionnaire explicitly asked questions about alcohol, cigarette, khat, and cannabis use as these are recognized as the most frequently tried from other studies [28]. Participants indicated their responses to the questionnaire with pen and paper.

2.4. Measurement. The outcome variable (dependent variable) was "alcohol use" among Dilla University students. Thus, the independent variables used for multiple logistic regression analysis were age, sex, religion, ethnicity, monthly income, place of residency, types of high school attended, current living, year of study, friends' psychoactive substance use, family's psychoactive substance use, diagnosis of mental illness, family history of mental illness, history of chronic illness, khat use, and cigarette smoking.

2.5. Data Quality Assurance. The pretest was done on students with $5 \%$ of the sample size in Hawassa University. Data collectors and supervisors were trained on the data collection tool and sampling techniques. Supervision was held regularly during the data collection period by both the researcher and supervisors. The wholeness and consistency of the data were crosschecked and cleaned manually.

2.6. Statistical Analysis and Processing. Data were entered into Epi Info version 7 computer programs and transported to SPSS version 20 computer program for further analysis and cleaning. Descriptive statistics were used to determine alcohol use and associated factors of participants. Tables were used for the data presentation. Associations of alcohol use variables and demographic characteristics were analyzed using the chi-square test, Fisher's exact test, and binary logistic regression with odds ratio and 95\% CI.

Multivariate logistic regression analysis was carried out to examine the associations between each independent variable and the outcome variable. The model was checked for fitness with $R$-squared value. An $R$-squared value greater than $50 \%$ was considered as good. Hosmer and Lemeshow goodness-of-fit test was also used to check the model fitness. All variables with a $p$ value of $\leq 0.25$ in the bivariable analysis were considered as the candidate for multivariable regression to control possible confounders. Finally, variables with a $p$ value of $<0.05$ were having a statistically significant association with alcohol use at corresponding 95\% CI.

2.7. Ethical Clearance. Ethical approval was obtained from the Institutional Review Board of Dilla University. The purpose and importance of the study were explained to each participant before they proceed into actual activities. Confidentiality was maintained by anonymous questionnaires, and informed consent was obtained from each participant.

\section{Results}

A total of 876 participants were recruited, and 803 participants completed the questionnaires sufficiently for analysis, giving the overall response rate of $91.7 \%$.

3.1. Sociodemographic Characteristics. Most of the study subjects were in the age group of 20-24 years $(81.7 \%$; $n=656)$, and most were male (66.9\%; $n=537)$, single (95.0\%; $n=763$ ), and Ethiopian Orthodox Tewahedo Christians (58.4\%; $n=469)$. Over half of the participants lived rurally before the university $(57.2 \% ; n=459)$, and almost all lived currently in halls of residence $(99.0 \% ; n=795)$. Most had attended a public high school $(88.9 \% ; n=714)$. (Table 1$)$.

3.2. Clinical Characteristics. Of the respondents, $6.4 \%$ $(n=51)$ reported a history of mental illness while $13.8 \%$ $(n=111)$ reported a family history of mental illness and $14.3 \%(n=115)$ had a chronic physical illness.

3.3. Habit of Alcohol Drinking in Respondents. Participants who have a habit of alcohol use were $41.8 \%$ $(n=336)$ and with current use in the last 30 days were $24.4 \%$ $(n=196)$. The most common reasons for alcohol use were for pleasure and to socialize $(18.7 \%(n=150)$ and $10.7 \%$ $(n=86)$, respectively).

Participants' main reasons for avoiding alcohol were for the religious and economic reasons $(19.3 \%(n=155)$ and $18.7 \%(n=150)$, respectively). However, the study participants' initiation of alcohol use was by friends and family $(19.1 \%(n=153)$ and $8.7 \%(n=70)$, respectively) (Table 2$)$.

3.4. Factors Associated with Alcohol Use among Students. In bivariate analyses, age, sex, religion, ethnicity, year of study, friends' use of psychoactive substances, family's psychoactive substance use, diagnosis of mental illness, family history of mental illness, history of chronic illness, khat use, and cigarette smoking were analyzed.

Multivariate logistic regression was also used to analyze associations between variables which have a $p$ value of $<0.2$ in bivariate logistic regression. After adjusting for possible covariates, year of study, being friends with psychoactive substance user, khat use, and cigarette smoking were significantly associated with alcohol use among students with a $p$ value $<0.05$ and with $R$-squared value of 0.573 (57.30 in percent).

Fourth-year students were about 2.66 times more likely to have alcohol use as compared to first-year students $(\mathrm{AOR}=2.66,95 \%$ CI: 1.64, 4.31).

Students having friends who were psychoactive substance users were 1.53 times more likely to use alcohol on the campus as compared with others $(\mathrm{AOR}=1.53,95 \% \mathrm{CI}$ : 1.09 , 2.1). 
TABLE 1: Sociodemographic characteristics of respondents at Dilla University, SNNPR, Ethiopia, 2018.

\begin{tabular}{|c|c|c|c|}
\hline Variables & Categories & Frequency & Percentage (\%) \\
\hline \multirow{2}{*}{ Sex } & Male & 537 & 66.9 \\
\hline & Female & 266 & 33.1 \\
\hline \multirow{3}{*}{ Age } & $15-19$ & 78 & 9.7 \\
\hline & $20-24$ & 656 & 81.7 \\
\hline & $25-30$ & 69 & 8.6 \\
\hline \multirow{3}{*}{ Marital status } & Married & 37 & 4.6 \\
\hline & Single & 763 & 95.0 \\
\hline & Divorced/widowed & 3 & 0.4 \\
\hline \multirow{4}{*}{ Religion } & Orthodox & 469 & 58.4 \\
\hline & Muslim & 134 & 16.7 \\
\hline & Protestant & 171 & 21.3 \\
\hline & Others* & 29 & 3.6 \\
\hline \multirow{5}{*}{ Ethnicity } & Oromo & 305 & 38.0 \\
\hline & Amhara & 289 & 36.0 \\
\hline & Gurage & 61 & 7.6 \\
\hline & Tigray & 114 & 14.2 \\
\hline & Others** & 34 & 4.2 \\
\hline \multirow{2}{*}{ Place of residence } & Urban & 344 & 42.8 \\
\hline & Rural & 459 & 57.2 \\
\hline \multirow{4}{*}{ Monthly income } & $<100$ & 49 & 6.1 \\
\hline & $101-299$ & 175 & 21.8 \\
\hline & $300-499$ & 285 & 35.5 \\
\hline & $>500$ & 294 & 36.6 \\
\hline \multirow{2}{*}{ Current life } & Dormitory & 795 & 99.0 \\
\hline & Nondormitory & 8 & 1.0 \\
\hline \multirow{3}{*}{ Type of high school attended } & Public high school & 714 & 88.9 \\
\hline & Private high school & 66 & 8.2 \\
\hline & Missionary high school & 23 & 2.9 \\
\hline \multirow{5}{*}{ Year of study } & $1^{\text {st }}$ year & 242 & 30.1 \\
\hline & $2^{\text {nd }}$ year & 232 & 28.9 \\
\hline & $3^{\text {rd }}$ year & 144 & 17.9 \\
\hline & $4^{\text {th }}$ year & 126 & 15.7 \\
\hline & $5^{\text {th }}$ year & 59 & 7.3 \\
\hline
\end{tabular}

${ }^{*}$ Catholic, Jehovah's witnesses, and no religion; ${ }^{* *}$ Gedeo, Wolayta, Siltie, and Sidama.

Those who had used khat were about 1.48 times more likely to have used alcohol compared to nonkhat users $(\mathrm{AOR}=1.48,95 \% \mathrm{CI}: 1.05,2.09)$. Those who smoked cigarettes were about 1.76 times more likely to use alcohol compared to nonsmokers $(\mathrm{AOR}=1.76,95 \% \mathrm{CI}: 1.09,2.84)$ (Table 3).

\section{Discussion}

The study has tried to determine the prevalence of alcohol use among 803 students and associated factors using a crosssectional study design and a semistructured questionnaire. The study participants were predominantly males $(66.9 \%$; $n=537)$, which is similar to previous studies $[11,18]$. Of the participants, $41.8 \%$ were lifetime users of alcohol, which is comparable to other Ethiopian student surveys $(40.8 \%$ in [23] and $40.2 \%$ in [24]). Alcohol prevalence was significantly lower than a similar study done in Kenya (51.9\%) [18] and Ethiopia (50.2\%) [29]. However, prevalence here was significantly higher than a similar study done in Axum University (34.5\%) [6] and Debre Markos University (33.8\%) in
Ethiopia [22]. The possible explanation for the observed difference could be due to the difference in alcohol accessibility, knowledge, and the study area.

The prevalence of current alcohol use in the last 30 days was $24.4 \%$. The finding was in line with a study done in Addis Ababa University among medical students (22\%) (25\% males vs. $14 \%$ females) [6], which is lower compared to a study done among Rift Valley University College students (35.6\%) in Ethiopia [24]. The possible reason might be the university setup and knowledge of the students.

The main reasons for alcohol use given by participants were for pleasure and to socialize $(18.7 \%(n=150)$ and $10.7 \%$ $(n=86)$, respectively). Similar studies done in Western Kenya among college students reported $62.2 \%$ or $60.8 \%$ to relax or relieve stress, respectively [18], a study in Ethiopia, among Debre Markos University students, reported 79.0\% for relaxation [22], and a study among Axum University students reported $65.5 \%$ for relaxation or $37.7 \%$ to relieve stress, respectively [21]. Also, a large proportion of the study participants were introduced to alcohol use by friends and family $(19.1 \%(n=153)$ and $70(8.7 \%(n=70)$, respectively), 
TAвLE 2: Frequency and percentage of alcohol drinking of respondents in Dilla University, SNNPR, Ethiopia, 2018.

\begin{tabular}{|c|c|c|c|}
\hline Variables & Categories & Frequency $(\%)$ & Percentage \\
\hline \multirow{2}{*}{ Alcohol use } & Yes & 336 & 41.8 \\
\hline & No & 467 & 58.2 \\
\hline \multirow{5}{*}{ Recurrence of alcohol use } & Every day & 26 & 3.2 \\
\hline & Once per week & 60 & 7.5 \\
\hline & 2-3 times per week & 33 & 4.1 \\
\hline & Current use in the last 30 days & 196 & 24.4 \\
\hline & Others & 21 & 2.6 \\
\hline \multirow{4}{*}{ Length of alcohol use } & 6 months & 48 & 6 \\
\hline & 1 year & 68 & 8.5 \\
\hline & 2 years & 86 & 10.7 \\
\hline & $>2$ years & 134 & 16.7 \\
\hline \multirow{6}{*}{ Reasons for alcohol use } & For pleasure & 150 & 18.7 \\
\hline & For academic purpose & 33 & 4.1 \\
\hline & To socialize & 86 & 10.7 \\
\hline & To prevent withdrawal effect & 11 & 1.4 \\
\hline & To pass time & 43 & 5.4 \\
\hline & Others & 13 & 1.6 \\
\hline \multirow{5}{*}{ Reasons for not using alcohol } & Religious reason & 155 & 19.3 \\
\hline & Health reason & 69 & 8.6 \\
\hline & Economic & 150 & 18.7 \\
\hline & Lack of desire & 43 & 5.4 \\
\hline & Others & 49 & 6.1 \\
\hline \multirow{2}{*}{ Intention for alcohol use } & Yes & 44 & 5.5 \\
\hline & No & 422 & 52.6 \\
\hline \multirow{6}{*}{ Initiation of alcohol use } & Friends & 153 & 19.1 \\
\hline & Religious custom & 26 & 3.2 \\
\hline & Accidental & 62 & 7.7 \\
\hline & Family & 70 & 8.7 \\
\hline & Traditional healers & 15 & 1.9 \\
\hline & Others & 9 & 1.1 \\
\hline \multirow{2}{*}{ Need for stopping alcohol use } & Yes & 94 & 11.7 \\
\hline & No & 241 & 30.0 \\
\hline \multirow{5}{*}{ Potential reasons for stopping alcohol use } & If I found that alcohol is a cause for my health problem & 224 & 27.9 \\
\hline & Immediately after graduation & 47 & 5.9 \\
\hline & If I have a financial problem & 29 & 3.6 \\
\hline & If my beloved is against it & 23 & 2.9 \\
\hline & Others & 12 & 1.5 \\
\hline
\end{tabular}

which is similar to studies done in Western Kenya among college students showing $75.1 \%$ by friends and $23.5 \%$ by relatives [18] and a study among Debre Markos Universtiy students is showing that $63 \%$ of students were introduced to alcohol use by friends in Ethiopia [22].

Here, alcohol use prevalence increased with the seniority of the students. The fourth-year students were about 3 times more likely to have alcohol use as compared to first-year students. Similar findings were reported in Hawassa and Haramaya Universities of Ethiopia [20, 23], Sudan [33], and Nigeria [34].

Students having friends who use psychoactive substances were 1.53 times more likely to use alcohol on the campuses as compared with their counterparts. The study is in line with a study done in Axum University among students; having family members and peer friends who drink alcohol were strongly associated with alcohol use [21]. Also, the finding was similar to a study done in Ethiopia among students whose friends consume alcohol were more likely to consume alcohol [35].
In this study, khat chewers had a strong association with alcohol use being about 1.48 times more likely to use alcohol as compared to counterparts. This study supported by studies of emergency hospital cases has found that a wide variety of controlled psychoactive substances are commonly taken before, along with, or after alcohol, and both substances are affecting the body [15]. The reason might require joint effect or augment to diminish or counteract the effect of the first substance.

Cigarette smoking had a strong positive association with alcohol use with smokers being twice as likely to use alcohol compared to their counterparts. Similarly, a study done in Ethiopia among students showed that the use of cigarette was also significantly associated with alcohol consumption $[21,36,37]$; the two tend to co-occur. The other common reason is that many cigarette smokers use alcohol to reduce the effect of smoking.

Chewing khat was also associated with alcohol use, with chewers being 1.48 times more likely to use alcohol 
TABLE 3: Bivariate and multivariate logistic regression analysis showing alcohol drinking among Dilla University students in Ethiopia, 2018.

\begin{tabular}{|c|c|c|c|c|c|}
\hline \multirow{2}{*}{ Variables } & \multirow{2}{*}{ Categories } & \multicolumn{2}{|c|}{ Alcohol use } & \multirow{2}{*}{ COR $(95 \%$ CI $)$} & \multirow{2}{*}{ AOR (95\% CI) } \\
\hline & & Yes & No & & \\
\hline \multirow{3}{*}{ Age } & $15-19$ & 26 & 52 & 1 & 1 \\
\hline & $20-24$ & 276 & 380 & $1.45(0.89,2.39)$ & $1.25(0.73,2.15)$ \\
\hline & $25-30$ & 34 & 35 & $1.94(1.00,3.74)$ & $1.01(0.47,2.20)$ \\
\hline \multirow{2}{*}{ Sex } & Male & 236 & 301 & $1.30(0.96,1.75)$ & $0.93(0.66,1.31)$ \\
\hline & Female & 100 & 166 & 1 & 1 \\
\hline \multirow{5}{*}{ Year of study } & $1^{\text {st }}$ year & 90 & 152 & 1 & 1 \\
\hline & $2^{\text {st }}$ year & 79 & 153 & $0.87(0.6,1.27)$ & $0.75(0.50,1.12)$ \\
\hline & $3^{\text {rd }}$ year & 60 & 84 & $1.21(0.79,1.84)$ & $0.98(0.62,1.55)$ \\
\hline & $4^{\text {th }}$ year & 77 & 49 & $2.65(1.7,4.13)$ & $2.66(1.64,4.31)^{* * *}$ \\
\hline & $5^{\text {th }}$ year & 30 & 29 & $1.75(0.99,3.10)$ & $1.47(0.77,2.81)$ \\
\hline \multirow{2}{*}{ Friends' PAS use } & Yes & 133 & 121 & $1.87(1.39,2.53)$ & $1.53(1.09,2.1)^{*}$ \\
\hline & No & 203 & 346 & 1 & 1 \\
\hline \multirow{2}{*}{ Family's PAS use } & Yes & 91 & 94 & $1.47(1.06,2.05)$ & $1.29(0.89,1.86)$ \\
\hline & No & 245 & 373 & 1 & 1 \\
\hline \multirow{2}{*}{ Khat use } & Yes & 153 & 157 & $1.559(1.17,2.07)$ & $1.48(1.05,2.09)^{*}$ \\
\hline & No & 183 & 310 & 1 & - \\
\hline \multirow{2}{*}{ Cigarette use } & Yes & 59 & 41 & $2.21(1.45,3.39)$ & $1.76(1.09,2.84)^{*}$ \\
\hline & No & 277 & 426 & 1 & 1 \\
\hline
\end{tabular}

${ }^{*} p$ value is significant at $p<0.05 .{ }^{* * *} p$ value is significant at $p<0.001$. PAS $=$ psychoactive substance.

than nonchewers. Studies of emergency hospital cases have also found that a wide variety of psychoactive substances are commonly taken before, along with, or after alcohol [15].

However, in contrast to other studies, here sex, age, family history of substance use, and student's origin of residence were not associated with alcohol use $[6,37,38]$.

\section{Conclusion}

In conclusion, the prevalence of alcohol use among students at Dilla University was high. Being a 4th-year student, having friends who use substances, being khat user, and being cigarette smoker were associated significantly with alcohol use. In Ethiopia, being a university student appears to increase alcohol use. The findings suggest that effective campus-based counselling and peer education should be implemented for early prevention, detection, and alleviation of alcohol use among students. Moreover, longitudinal studies should be showed to check the reproducibility of alcohol use among university students in Ethiopia.

\section{Abbreviations}

ASSIST: Alcohol, Smoking, and Substance Involvement Screening Test

DU: Dilla University

Epi Epidemiological Information

Info:

PAS: $\quad$ Psychoactive substance

RVUC: Refit Valley University College

SNNPR: Southern Nations, Nationalities, and People's Region

SPSS: Statistical Package for Social Science

WHO: World Health Organization.

\section{Data Availability}

The data used to support the finding of this study are available from the author upon request.

\section{Additional Points}

This study did not do a detailed validation of the alcohol screening tool. The collected data were measured using a self-reported questionnaire, but it was safeguarded anonymity to reduce subjectivity bias. The cross-sectional nature of the study design might not show the causal relationships between sociodemographic and risk factors and alcohol use.t

\section{Ethical Approval}

Ethical clearance was obtained from the Institutional Review Board (IRB) of Dilla University.

\section{Consent}

Formal permission was obtained from students, and finally, written consent was obtained from each participant during data collection. All participants were well informed about the aims and purpose of the study and its contribution to the future development of the health system in the universities and the country. Those participants were informed that the right is given to the study participants to refuse and stop or withdraw from participation at any time during data collection without loss of any entitlement.

\section{Conflicts of Interest}

The author declares that he has no conflicts of interest. 


\section{Authors' Contributions}

YA conceived the research question, participated in the proposal development, data collection, analysis, and interpretation, and critically reviewed the manuscript.

\section{Acknowledgments}

The author would like to thank the study participants for investing their fruitful time to participate in the study. Gratitude also goes to Dilla University Research Dissemination Office for positive cooperation and support in the study process.

\section{References}

[1] M. Windle and R. C. Windle, "Depressive symptoms and cigarette smoking among middle adolescents: prospective associations and intrapersonal and interpersonal influences," Journal of Consulting and Clinical Psychology, vol. 69, no. 2, p. 215, 2001.

[2] J. D. Hawkins, R. F. Catalano, and J. Y. Miller, "Risk and protective factors for alcohol and other drug problems in adolescence and early adulthood: implications for substance abuse prevention," Psychological Bulletin, vol. 112, no. 1, p. 64, 1992.

[3] S. W. Acuda, "Drug dependence: health and socio-economic consequences," East African Medical Journal, vol. 65, no. 10, p. 643, 1988.

[4] A. O. Odejide, "Status of drug use/abuse in Africa: a review," International Journal Of Mental Health And Addiction, vol. 4, no. 2, pp. 87-102, 2006.

[5] World Health Organization, Global Status Report on Alcohol and Health, Vol. 2013, World Health Organization, Geneva, Switzerland, 2011.

[6] W. Deressa and A. Azazh, "Substance use and its predictors among undergraduate medical students of Addis Ababa University in Ethiopia," BMC Public Health, vol. 11, no. 1, p. 660, 2011.

[7] World Health Organization, Global Status Report on Alcohol and Health-2014, World Health Organization, Geneva, Switzerland, 2014.

[8] World Health Organization, Building Back Better: Sustainable Mental Health Care after Emergencies, World Health Organization, Geneva, Switzerland, 2013.

[9] J. Rehm, C. Mathers, S. Popova, M. Thavorncharoensap, Y. Teerawattananon, and J. Patra, "Global burden of disease and injury and economic cost attributable to alcohol use and alcohol-use disorders," The Lancet, vol. 373, no. 9682, pp. 2223-2233, 2009.

[10] P. R. Giancola, R. A. Josephs, D. J. Parrott, and A. A. Duke, "Alcohol myopia revisited," Perspectives on Psychological Science, vol. 5, no. 3, pp. 265-278, 2010.

[11] P. Okwarah, R. Gakunju, E. Kabiru et al., "Prevalence and correlates of alcohol use among underage high-school students in murang' a and kajiado counties, Kenya," Journal of Public Health, vol. 1, no. 6, 2015.

[12] World Health Organization, Global Status Report on Alcohol and Health, World Health Organization, Geneva, Switzerland, 2018.

[13] World Health Organization, Technical Consultation on the Public Health Problems Caused by Harmful Use of Alcohol in the African Region, World Health Organization, Geneva, Switzerland, 2007.

[14] E. Bass and P. Gill, "Report into "on the day cancellations" for plastic surgery in patients who failed to stop their medication," British Medical Journal Open Quality, vol. 3, no. 1, 2014.

[15] Substance Abuse and Mental Health Services Administration, Results from the 2013 National Survey on Drug Use and Health: Summary of National Findings, Substance Abuse and Mental Health Services Administration, NSDUH Series H-48, HHS Publication No. (SMA) 14-4863, Substance Abuse and Mental Health Services Administration, Rockville, MD, USA, 2014.

[16] G. Alleyne, J. Breman, M. Claeson et al., Disease Control Priorities in Developing Countries, World Bank/Oxford University Press, Washington, DC, USA, 2006.

[17] World Health Organization, Department WHOSA, Abuse S. Global Status Report on Alcohol 2004, World Health Organization, Geneva, Switzerland, 2004.

[18] L. Atwoli, P. A. Mungla, M. N. Ndung'u, K. C. Kinoti, and E. M. Ogot, "Prevalence of substance use among college students in Eldoret, western Kenya," BioMed Central Psychiatry, vol. 11, no. 1, pp. 1-9, 2011.

[19] D. Kebede, A. Alem, G. Mitike et al., "Khat and alcohol use and risky sexual behaviour among in-school and out-ofschool youth in Ethiopia," BioMed Central Public Health, vol. 5, no. 1, p. 109, 2005.

[20] G. Tesfaye, A. Derese, and M. T. Hambisa, "Substance use and associated factors among university students in Ethiopia: a cross-sectional study," Journal of Addiction, vol. 2014, Article ID 969837, 8 pages, 2014.

[21] M. Gebreslassie, A. Feleke, and T. Melese, "Psychoactive substances use and associated factors among Axum University students, Axum Town, North Ethiopia," BioMed Central Public Health, vol. 13, no. 1, p. 693, 2013.

[22] G. Tsegay, "Psychoactive substances use (khat, alcohol and tobacco) and associated factors among Debre Markos University Students, North-West Ethiopia," Journal of Defense Management, vol. 2014, 2013.

[23] A. Kassa, F. Taddesse, and A. Yilma, "Prevalence and factors determining psychoactive substance (PAS) use among Hawassa University (HU) undergraduate students, Hawassa Ethiopia," BioMed Central Public Health, vol. 14, no. 1, p. 1044, 2014.

[24] S. Kumesa, M. Mohammed, E. Gebremariam, B. Gelaw, and M. Seifu, "The prevalence and pattern of social drug abuse among students of rift Valley University college, Bishoftu campus, 2014, Bishoftu, Ethiopia," Journal of Pharmaceutical Care \& Health Systems, vol. 2, no. 1, 2015.

[25] A. Fekadu, A. Alem, and C. Hanlon, "Alcohol and drug abuse in Ethiopia: past, present and future," African Journal of Drug and Alcohol Studies, vol. 6, no. 1, pp. 40-53, 2007.

[26] Population Census Commission, Summary and Statistical Report of the 2007 Population and Housing Census: Population Size by Age and Sex, Population Census Commission, Addis Ababa, Ethiopia, 2008.

[27] Population Census Commission, Summary and Statistical Report of the 2007 Population and Housing Census, Population Census Commission, Addis Ababa, Ethiopia, 2008.

[28] R. Humeniuk, S. Henry-Edwards, R. Ali, V. Poznyak, and M. G. Monteiro, The Alcohol, Smoking and Substance Involvement Screening Test (ASSIST): Manual for Use in Primary Care, World Health Organization, Geneva, Switzerland, 2010.

[29] World Health Organization, WHO Report on the Global Tobacco Epidemic, 2011: A Warning about the Dangers of Tobacco, World Health Organization, Geneva, Switzerland, 2011. 
[30] J. u. r. Rehm, R. Room, M. Monteiro et al., "Alcohol as a risk factor for global burden of disease," European Addiction Research, vol. 9, no. 4, pp. 157-164, 2003.

[31] Drugs Oo, Crime, World Drug Report 2014, United Nations Development Programme, New York, NY, USA, 2014.

[32] World Health Organization, "World health report 2002," Reducing Risks, Promoting Healthy Life, World Health Organization, Geneva, Switzerland, 2002.

[33] G. K. Padhy, S. Das, T. Sahu, and S. Parida, "Prevalence and causes of substance abuse among undergraduate medical college students," Indian Medical Gazette, vol. 148, no. 8, pp. 276-282, 2014.

[34] C. Duru, U. Oluoha, C. Okafor et al., "Socio-demographic determinants of psychoactive substance use among students of tertiary institutions in Imo State, Nigeria," Journal of Addiction Research \& Therapy, vol. 8, no. 2, 2017.

[35] Y. Kebede, T. Abula, B. Ayele, A. Feleke, G. Degu, and A. Kifle, "Substances abuse for the Ethiopian health center team," Ethiopia Public Health Train Initiative, vol. 81, 2005.

[36] F. Lewin, S. E. Norell, H. Johansson et al., "Smoking tobacco, oral snuff, and alcohol in the etiology of squamous cell carcinoma of the head and neck," Cancer, vol. 82, no. 7, pp. 1367-1375, 1998.

[37] T. Mekonen, W. Fekadu, T. Chane, and S. Bitew, "Problematic alcohol use among university students," Frontiers in Psychiatry, vol. 8, p. 86, 2017.

[38] A. Kassa, N. Wakgari, and F. Taddesse, "Determinants of alcohol use and khat chewing among Hawassa University students, Ethiopia: a cross sectional study," African Health Sciences, vol. 16, no. 3, pp. 822-830, 2016. 